\title{
Structural characteristics of the basement and the prospective of favorable oil and gas blocks in the Tacheng basin*
}

\author{
Guoqing Zhang ${ }^{1, \star} \quad$ Junmeng Zhao ${ }^{2} \quad$ Hua Bai $^{1}$ \\ Ming Wan $^{1}$ and Xiaoyang Guo ${ }^{1}$ \\ ${ }^{1}$ Research Institute of Exploration and Development, Xinjiang Oilfield Company, \\ PetroChina, Karamay 834000, China \\ ${ }^{2}$ Institute of Tibetan Plateau Research, Chinese Academy of Sciences, Beijing 100101, China
}

\begin{abstract}
The Tacheng basin has been identified as a Carboniferous basement with a central uplift, surrounded by orogenic belts. This identification was based on the comprehensive analysis of field outcrops, regional magnetic and gravimetric data, skeleton seismic profiles, magnetotelluric profiles and drilling data. Here, we present gravimetric and magnetic data analyses of the basement structures of the Tacheng basin and its base formation. We also provide a magnetotelluric profile analysis of the structural features and tectonic framework of basin-mountain patterns. We use local geology, drilling data, and other comprehensive information to document the tectonic framework of the basement of the basin. Small-scale nappe structures are found in the northern basin, whereas stronger and more pronounced thrusting structures are found to the south and east of the basin. The basin is divided into four first-order tectonic units: a central uplift, a northern depression, a southeastern depression and a western depression. In addition, the Emin sag is suggested as a possible reservoir for oil and gas.
\end{abstract}

Key words: northern Xinjiang; Tacheng basin; basement structure; basin and mountain relationship; tectonic unit division; favorable area

CLC number: P315.2 Document code: A

\section{Introduction}

The Tacheng basin is located in northwestern North-Xinjiang, which is surrounded by the Taerbahatai mountains to the north, the Xiemisitai and Wuerkashier mountains to the east, and the Baerluke mountains to the south. The length of the basin is $\sim 160 \mathrm{~km}$ in the west-east direction and the width of the basin is $\sim 90 \mathrm{~km}$. The total surface area is $\sim 8300 \mathrm{~km}^{2}$ (Figure 1). The Tacheng basin is a Cenozoic multi-cyclic sedimentary intermontane basin that developed on folded Paleozoic basement rock. Tectonically, the basin is located on the eastern Kazakhstan plate

\footnotetext{
* Received 26 August 2012; accepted in revised form 14 October 2012; published 10 December 2012.

+ Corresponding author. e-mail: zhgq@petrochina.com.cn

(c) The Seismological Society of China, Institute of Geophysics,

China Earthquake Administration, and Springer-Verlag Berlin Heidelberg 2012
}

and western Junggar fold belt, stretching across China and Kazakhstan (Dong et al., 2010).

The Tacheng basin is almost entirely covered by Neogene and Late Carboniferous to Early Permian volcanic rocks. Granite outcrops are found in the central and western sections of the basin. Only a small section of Paleogene rock outcrops at the edge of the basin (for strata thicknesses, see Table 1). Mesozoic rocks are lacking although the Paleozoic, Paleogene and Neogene are represented. In the periphery of the basin, the most prevalent rocks are from the Upper Paleozoic and the Middle and Upper Devonian. There are relatively few Lower Carboniferous rocks, and only a few Lower Permian sections have been identified (Wang and Wu, 1990).

Geological exploration of the basin began in 1959 and includes completed 1:200 000 regional geological mapping, 1:200 000 gravity and magnetic census and a 1:100 000 aeromagnetic survey. Two skeleton seismic 


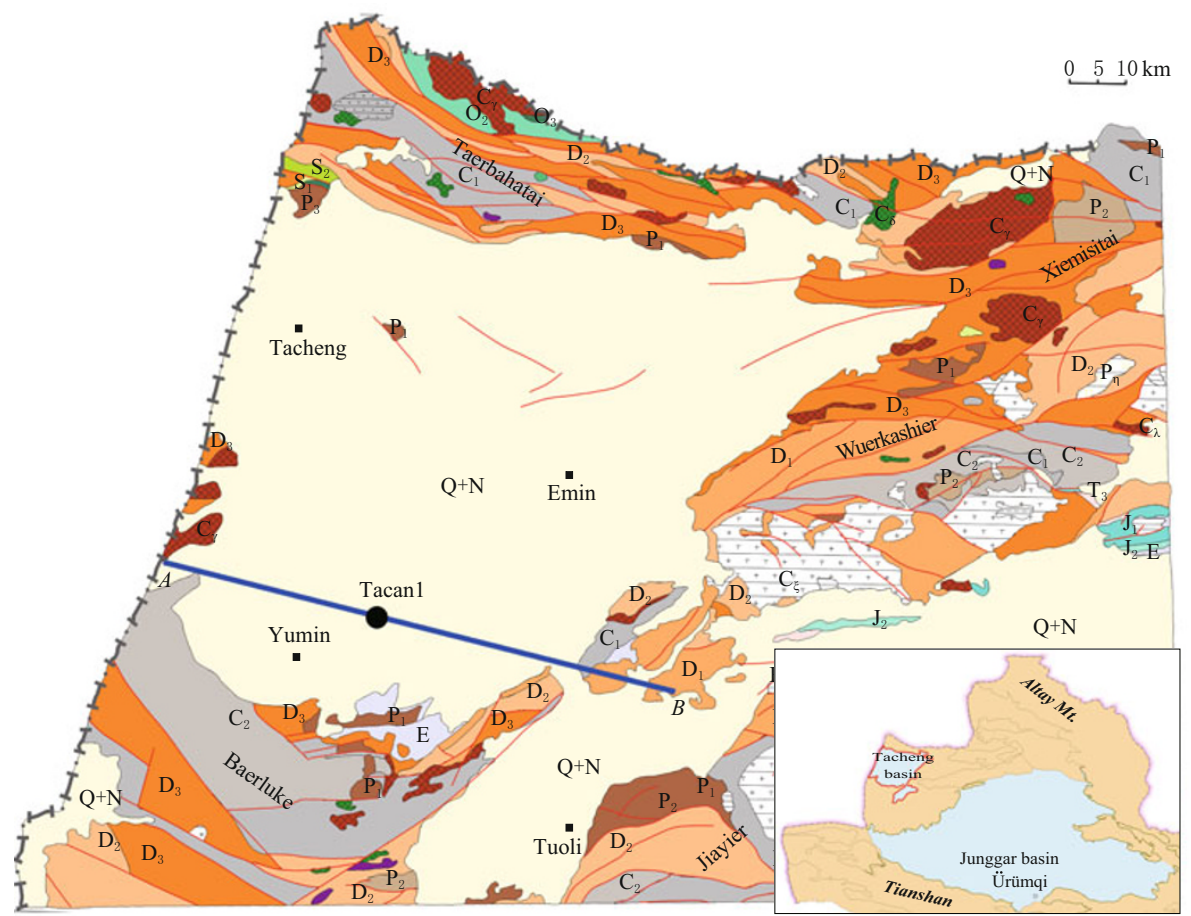

Figure 1 Schematic diagram of the Tacheng basin in northern Xinjiang where the $A B$ is a CEMP profile and Tecan 1 (denoted by a big dot) is a well drilled in the basin.

profiles were carried out across the basin in 2007, as well as a continuing electrical-magnetic profile (CEMP). Only one well has been drilled in the basin (Tacan 1 in 2009), which extends to $3300 \mathrm{~km}$ in depth, through several different strata: Neogene, Paleogene, Permian and Carboniferous.

\section{Structural features of the base- ment rock}

\subsection{The physical properties of the strata}

According to statistics on the physical properties in the western Junggar and Tacheng areas (Table 1), we observe a medium to weak magnetic field in the Paleozoic rocks and no magnetic field in the Cenozoic. This finding may be attributable to the frequent volcanic eruptions in the region. The Middle-Upper Devonian magnetic sequence is more pronounced than the Carboniferous magnetic section. There is a larger density difference between the Permian and Paleogene sections, with a density contrast up to $0.16 \mathrm{~g} / \mathrm{cm}^{3}$. This is largely due to the missing Mesozoic signal. Likewise, the Carboniferous and Permian density difference is $0.13 \mathrm{~g} / \mathrm{cm}^{3}$. The density of the Devonian and deeper strata increases gradually over a small gradient. The most obvious density differences are found between the

Table 1 Formation properties of the West Junggar and Tacheng basins

\begin{tabular}{|c|c|c|c|c|c|c|c|c|}
\hline \multirow{2}{*}{ Strata unit } & \multirow{2}{*}{ Symbol } & \multirow{2}{*}{$\begin{array}{c}\text { Thickness } \\
\text { /m }\end{array}$} & \multicolumn{2}{|c|}{ Magnetic susceptibility/( $\left.10^{-5} 4 \pi \mathrm{SI}\right)$} & \multicolumn{2}{|c|}{ Density $/\left(\mathrm{g} \cdot \mathrm{cm}^{-3}\right)$} & \multicolumn{2}{|c|}{ Resistivity $/(\Omega \cdot \mathrm{m})$} \\
\hline & & & Changes & Average & Changes & Average & Changes & Average \\
\hline Neogene & $\mathrm{Q}$ & $0-200$ & & & $1.58-2.05$ & 1.75 & 1517 & 1517 \\
\hline Paleogene & $\mathrm{N}+\mathrm{E}$ & $0-250$ & & & $2.04-3.52$ & 2.31 & 596 & 596 \\
\hline \multirow[t]{2}{*}{ Permian } & $\mathrm{P}_{2}$ & $0-300$ & $0-700$ & 62 & $2.07-2.70$ & 2.47 & & \\
\hline & $\mathrm{P}_{1}$ & $214-922$ & $0-210$ & 20 & & & & \\
\hline \multirow[t]{2}{*}{ Carboniferous } & $\mathrm{C}_{2}$ & $0-3000$ & $0-4000$ & 180 & $1.60-2.81$ & 2.60 & 10507 & 10507 \\
\hline & $\mathrm{C}_{1}$ & $1032-3041$ & $0-5500$ & 234 & & & $5385-12315$ & 7755 \\
\hline \multirow[t]{3}{*}{ Devonian } & $\mathrm{D}_{3}$ & $492-2942$ & $0-8000$ & 574 & $2.38-2.75$ & 2.65 & 9040 & 8636 \\
\hline & $\mathrm{D}_{2}$ & $1194-3520$ & $0-7000$ & 672 & & & 8607 & \\
\hline & $\mathrm{D}_{1}$ & $316-1207$ & & 41 & & & 8261 & \\
\hline \multirow[t]{2}{*}{ Silurian } & $\mathrm{S}_{3}$ & 0-744 & $0-1150$ & & $2.37-2.93$ & 2.68 & & \\
\hline & $\mathrm{S}_{2}$ & $472-3674$ & & & & & & \\
\hline
\end{tabular}


Permian and Paleogene and the Carboniferous and Permian sections, which are also the main gravity anomaly interfaces in the Tacheng basin. The resistivity also varies regularly, increasing through the geologic section from older to younger rocks. The minimum resistivity of the Paleogene is $\sim 596 \Omega \cdot \mathrm{m}$, and the maximum resistivity of the Devonian is $\sim 8636 \Omega \cdot \mathrm{m}$. We postulate that the large density contrast in this area is caused by the Carboniferous, Devonian and deeper older stratum.

\subsection{The structure of the basin basement rock}

The Tacheng basin, composed of Early Paleozoic and Late Paleozoic structural layers, is part of the Junggar plate in Kazakhstan and is situated at the western end of the Sawuer-Ertai Late Paleozoic trench-arc system. The basin is composed of Late Ordovician volcanic rocks and Carbonates, Silurian clastic rocks, EarlyMiddle Devonian and Early Carboniferous volcanic fly- sch, Middle Carboniferous acidic volcanic rocks, Permian continental molasses, and calc-alkaline volcanics (Zhang et al., 1990)

The foundation for this study is based on the Upper Carboniferous-Lower Permian outcrops in the basin, the regional magnetic and gravimetric data, the skeleton seismic profile and the magnetotelluric profiles. The residual gravity anomaly (the Bouguer gravity anomaly subtracted by the upward continuous $(3 \mathrm{~km})$ gravity anomaly) in the Tacheng basin and its surrounding area clearly reflects the tectonic pattern of the region (Figure 2). The main part of the basin is located in the western end of the Sawuer-Ertai Late Paleozoic arc groove of structural units, and in the southeastern part of the Xiemisitai-Maiqinwula Paleozoic arc groove of structural units.

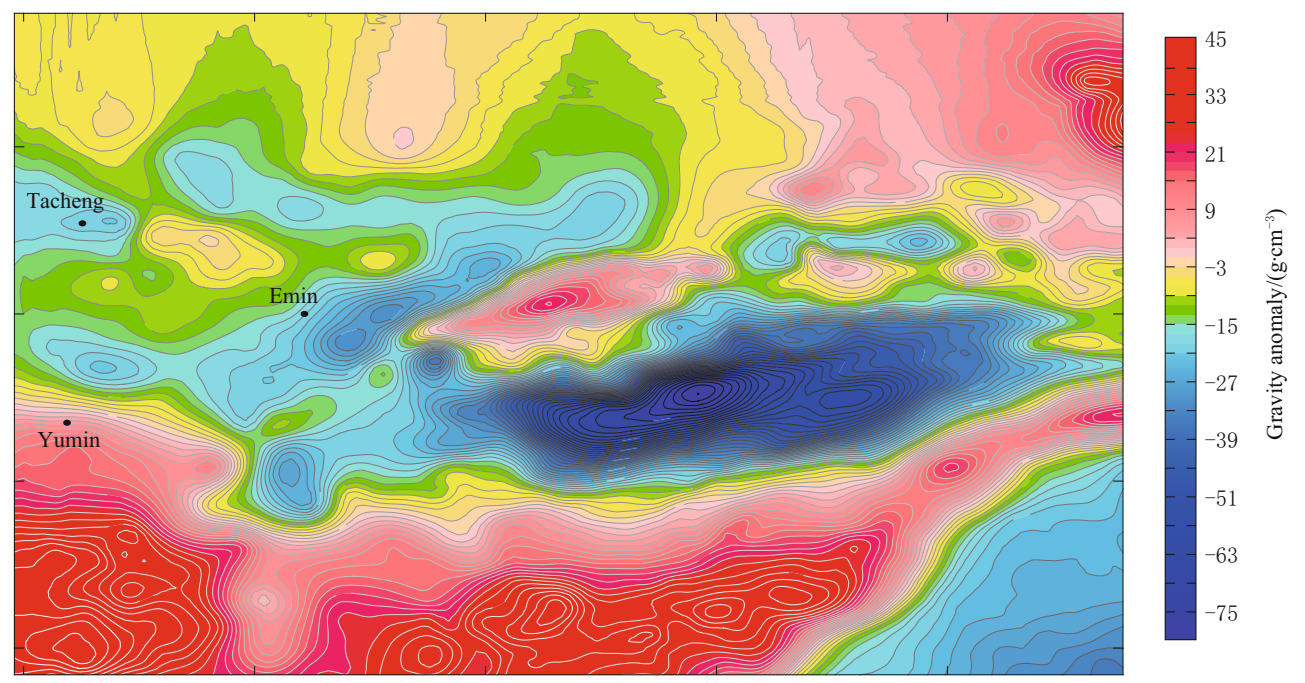

Figure 2 Residual gravity anomalies in the Tacheng basin.

We find that the Tacheng basin residual gravity anomalies are expressed as a zonal ring of low gravity anomalies, with a more open pattern occurring westward. The low gravity anomaly region is bounded by relatively high gravity anomalies (to the north, east, and south). Residual gravity anomalies reflecting the low gravity of the belt correspond to: (1) a NE-trending depression to the south, (2) an EW-trending depression to the north, (3) a westward depression to the west, and (4) a central uplift. Peripheral areas of high gravity include the northern Taerbahatai mountains, the eastern Xiemisitai and Wuerkashier mountains, and the southern Baerluke mountains.

The residual gravity anomalies in the southeastern Xiemisitai-Maiqinwula Paleozoic trench-arc system are comprised of largescale low gravity anomalies and a largescale high gravity anomaly. The low gravity anomalies correspond to the Heshituoluogai basin, and the southern high gravity anomaly corresponds to the Jiayier mountains.

According to the property analysis of the formations, the Permian, Paleogene and Carboniferous sections of the Tacheng basin demonstrate the most obvious density contrast. Taking the thin stratum and the distribution limits of the Permian section of the Tacheng basin into account, the Carboniferous and the Paleogene rocks in the area show the maximum density interface in the region. In other words, the main reasons for the residual gravity anomaly are the rocks found in the Carboniferous and Devonian sections. 
The field geological survey found that Carboniferous and Permian outcrops are located in the high gravity anomaly section of the central part of the basin. The thickness of the Permian, detected by the Tacan 1 well, is $\sim 431 \mathrm{~m}$. In addition, the two skeleton seismic profiles across the basin also show that the Permian section is relatively thin, and the medium to weak high gravity anomaly of the Permian is about $3 \times 10^{-5} \mathrm{~m} / \mathrm{s}^{2}$. According to theses observations, the central uplift area has Carboniferous outcrops in the basin, so it is believed to have been caused by the basement stratum of the Carboniferous. The relatively low gravity anomaly located in the southeast of the basin has a strength of $-25 \times 10^{-5} \mathrm{~m} / \mathrm{s}^{2}$ and is the largest anomaly in the basin. We suggest, based on the analysis of well-data and seismic profiles, that the low gravity anomaly is caused primarily by the Permian and Cenozoic basement rock. In the north, the basement is found at shallower structural levels, and lower gravity signals $\left(-11 \times 10^{-5} \mathrm{~m} / \mathrm{s}^{2}\right)$ are probably caused by the Cenozoic section. The low gravity anomaly $\left(-15 \times 10^{-5} \mathrm{~m} / \mathrm{s}^{2}\right)$ located in the west of the basin extends to Kazakhstan. This formation is similar to that of the northern basin. Following these explanations, the high residual gravity anomalies located in the southern edge of the basin are likely caused by the Middle-Upper Devonian orogenic belt (Baerluke mountains). The southeastern anomaly is caused by the Middle-Upper Devonian orogenic belt (Xiemisitai mountains) and the anomaly located at the north edge of the basin is caused by the Devonian and Carboniferous orogenic belt (Taerbahatai mountains).
The continuous $\sim 100 \mathrm{~m}$ high aeromagnetic anomalies, which are composed of medium-weak negative magnetic anomalies in the middle of the basin, show relatively positive magnetic anomalies in the central region. They also exhibit a NE-trending positive magnetic anomaly zone in the south. This reflects the development of the basin and periphery volcanoes (Figure 3; Bureau of Geology and Mineral Resources in Xinjiang, 1985).

The medium to weak negative magnetic anomalies in the basin correspond well to the low gravity anomalies of the south-east, north and west parts of the basin. This indicates that the negative magnetic anomaly zones are favorable areas of Permian and Cenozoic sedimentary filling. The high magnetic anomalies in the central region correspond to Carboniferous and Permian outcrops, indicating that these anomalies are mainly caused by Carboniferous rocks. The high magnetic anomaly in the southern area corresponds to the presence of the Baerluke and Xiemisitai mountains. Considering the outcrop analysis, we conclude that the Devonian has strong magnetism and is widely distributed. We further infer that the strong magnetic anomalies in the southern edge of the basin are probably caused by the Devonian orogenic belt.

Gravity and magnetic anomalies clearly reflect that the Tacheng basin is an annular depression with a Carboniferous central uplift. It is also surrounded by orogenic belts that are cored by Carboniferous basement rocks.

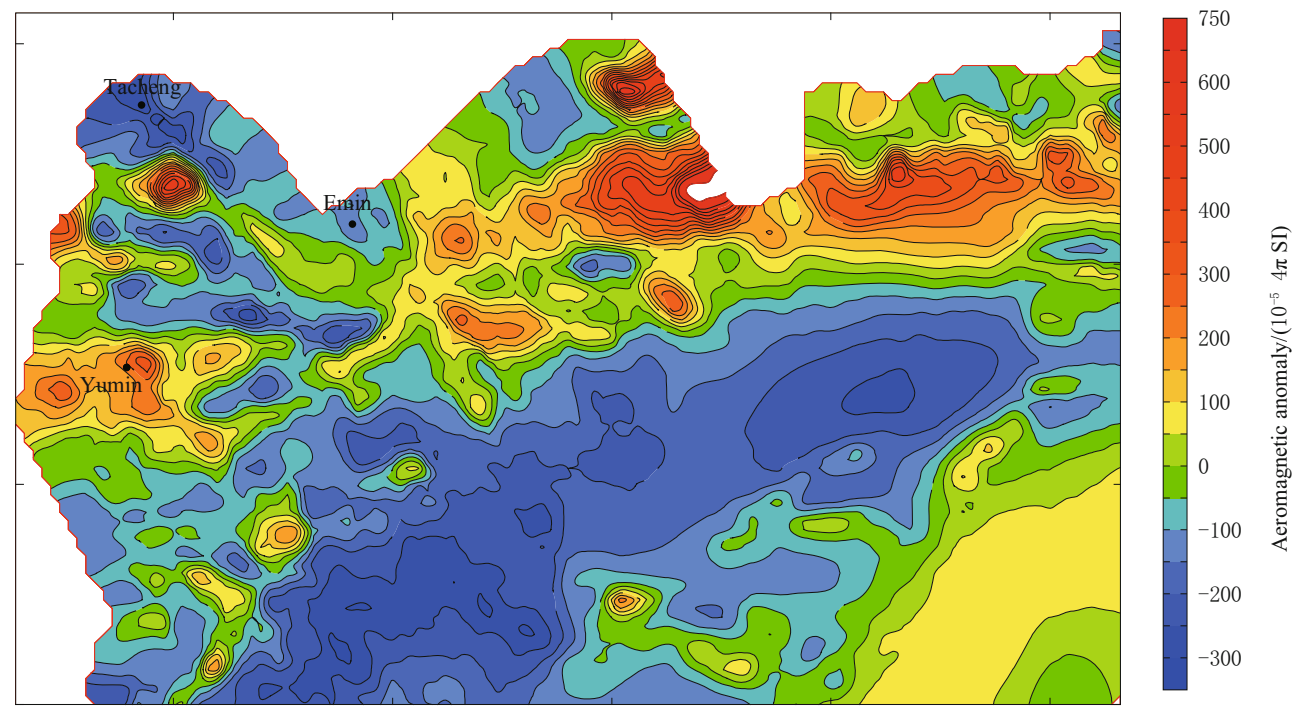

Figure 3 Aeromagnetic anomalies extended $1000 \mathrm{~m}$ in the Tacheng basin. 


\section{Relationship between the basin and the mountains}

With the exception of the western section, the Tacheng basin is in direct contact with the surrounding mountains. The TC2007E01 line of the magnetotelluric survey is the only CEMP (continuing electricalmagnetic profile) section in the southern basin (Figure 4), which crosses the southern and eastern parts of the basin. Data processing consisted mainly of static displacement corrections and apparent resistivity conversion. The basin-mountain structural section was obtained by BOSTICK inversion. The eastern limit of the profile is in the Baerluke mountains, and the western limit in the Wuerkashier mountains, respectively. In the western part of the profile, there is a thrusting nappe of basin rock, and evidence of erosion and partial erosion of the Carboniferous section in the sub-surface. There is an overthrust of folded rocks in the basin and a clear piedmont dustpan-like style of deposition with evidence of multiple thrusting events that were induced by the uplift of the Carboniferous section to the near-surface. The central part of the section consists of the southeastern depression of the southern Tacheng basin. The lower resistivity of the Cenozoic section is detected near the surface, the normal resistivity of the Carboniferous section is detected at middle-deep depths, including a small Permian section. The higher resistivity of the Devonian strata is found at deeper depths. The scale and intensity of the eastern section of the overthrust nappe is relatively small compared to the rest of the nappe. The Carboniferous section is overlapping and thinning, until it outcrops, and then the Devonian section and lower strata start to uplift.

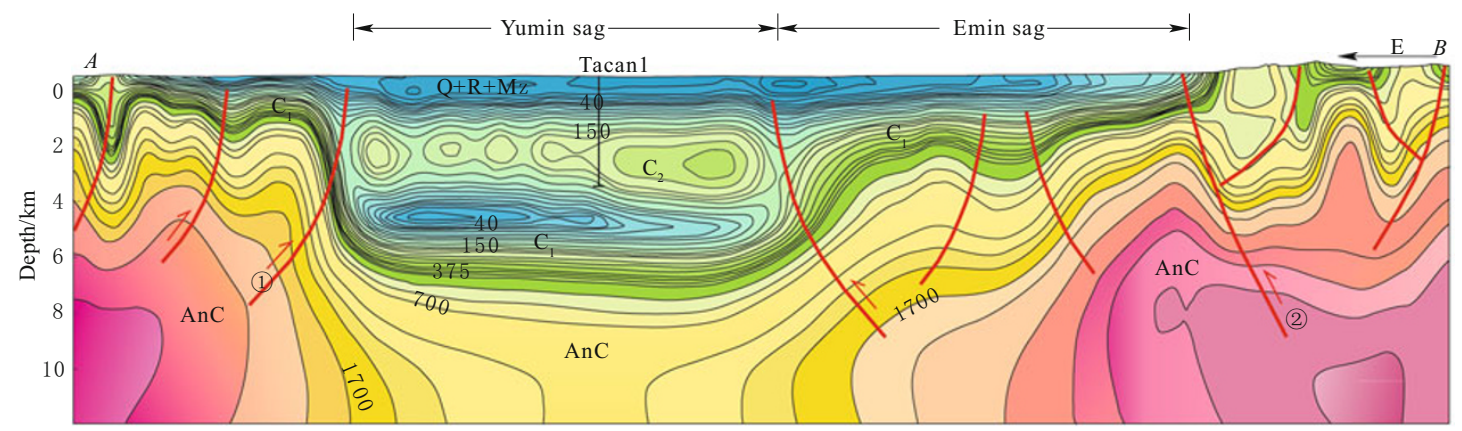

Figure 4 A structural cross-section depicting the geological interpretation of the Tacheng basin along the TC2007E01 line.

The CEMP profile clearly reflects the macroscopic electrical structure in the study area, the characteristics of the development of the formation, and the basinmountain relationships between the southern and eastern ends of the basin (Feng, 2009). We postulate that the northern basin has a normal unconformity contact relationship, as only small-scale over-thrusting structures are found. This assessment is based on ground geological investigations and a derivation of the basement structure of the basin from gravity and magnetic data. The eastern and southern parts of the basin are part of a strong fold system that verges towards the basin. In particular, the relatively strong thrusting nappe structure in the southeast has formed a region of large-scale mountain-front sedimentary deposition.

\section{The evolution of the basin}

The main body of the Tacheng basin is located in the Late Paleozoic era epicontinental volcanic rock belt, which was formed as the Neopaleozoic arc-shaped archipelago basin grew. Marine deposits formed in an Early Devonian marine transgression followed by a regression in the Late Devonian. Basalts dominate the Lower Devonian volcanic rock sequence, whereas liparite-basalts dominate the Middle Devonian. The twin peak characteristics are obvious. After this sequence, another transgression-regression cycle began. Shallow littoral facies deposition occurred during the Carboniferous, but intermediate-basic, intermediateacidic volcanic rock and volcanoclastic rocks are also prevalent. The formation of the continental and paralic volcano molasses began in the early stage of Late Carboniferous and the formation of sedimentary clastic molasse in the later period.

The construction of the Tacheng basin and its neighboring orogenic belt is divided into two stages of tectonic evolution.

1) The Ordovician-Silurian. SHRIMP geochronol- 
ogy of altered Taerbahatai ophiolite mélange shows that the gabbro was formed in $478.3 \pm 3.3 \mathrm{Ma} \mathrm{BP}$. This indicates that the snake suite was formed in the Early Ordovician. The Tangbalei ophiolite in the western Junggar of the southern side is located in the Middle Ordovician Kekeshayi group, in siliceous rocks containing a large number of Middle Ordovician radiolarian fossils, indicating that an ocean basin formed during the Late Cambrian-Early Ordovician (Zhang and Huang, 1992). This process ended in the Late Ordovician, after the emplacement of an Early Silurian terrain (Zhu and Feng, 1994). In recent years the discovery of the Karamay ophiolite belt and the study of the Taerbahatai ophiolite belt of west Junggar have been confirmed as part of the Early Paleozoic paleo-Asian ocean, or starting from the Late Neoproterozoic era development. After the Silurian continental collision and collage, the West Junggar and metamorphic basement structures formed in Tacheng.

2) Devonian-Late Carboniferous: Evolution of the folded basement from the Early Devonian to Early Carboniferous epoch. This period marked the early formation and evolution of the continental crust (stabilization). Early Paleozoic basement rock underwent a stabilization process, including back-arc extension. The sediments consist of marginal volcanic rock and remnant ocean basin rock. Due to a strong sense of deep crust-mantle interaction, strong rift activity is apparent, which formed an extensive aulacogen that induced the development of volcanic and intrusive rock formations. At the end of Late Carboniferous, the central Asian ocean basin disappeared and the era of post-collision be- gan. This period was marked by large-scale continental volcanic activity and extensive development of volcanic Molasse construction.

\section{Division of the tectonic units}

The Tacheng basin underwent several tectonic episodes, including an Early Paleozoic ocean-land transformation phase. Remnants of a Late Paleozoic oceanic basin and a continental volcanic molasse stage formed on top of the Cenozoic basement rock. Different characteristics have been identified between the northern and southern borders of the basin. Relatively weaker tectonic activity appears in the northern border, showing weak compressive action and unconformity between the Cenozoic formation and the old formation. In contrast, strong compressions appear to have occurred in the southern and eastern limits of the northeast-trending basin-mountain zone. According to overtrusting regions that border the basin, north-east trending mountain front depressions were generated in the southern basin. The western part of the basin extends to Kazakhstan, influencing the integrity of the depression.

The basement structure of the Tacheng basin in the Late Paleozoic was interpreted from the inversion of gravity anomalies (Figure 5). This divided the Tacheng basin into four first-order tectonic units: a central uplift, a northern depression, a depression in the southeast and a western depression. The central uplift is located in the basin basement uplift of the central area (Feng et al., 2009), and the Carboniferous bedrock outcrops are found in the northwest. The northern depression

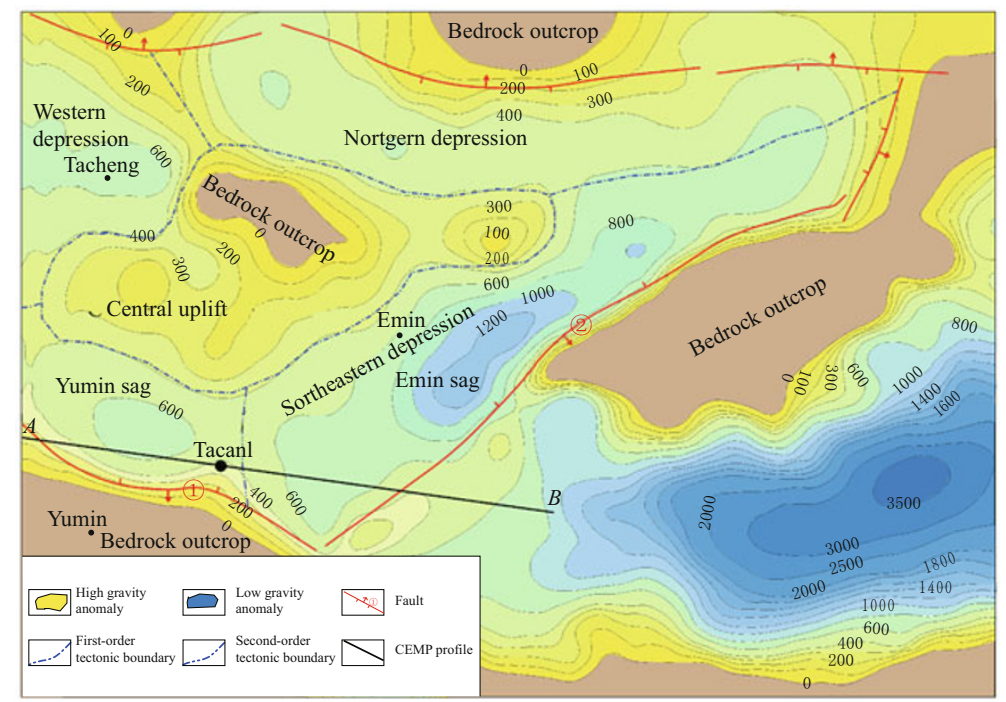

Figure 5 Schematic diagram and division of the basement rock in the Tacheng basin. 
is a near east-west-trending depression belt located in northeastern Tacheng, south of the Tarbagatay range. The depth of the Paleozoic basement is $\sim 500 \mathrm{~m}$. The depression in the southeast is a foredeep zone surrounding the south-east-trending ancient bedrock. The deepest depressions of the Tacheng basin in this region are the Xiemisitai mountain foredeep $(\sim 1100 \mathrm{~m})$, and the Baerluke mountain depression in the south $(\sim 600 \mathrm{~m}$ deep). The western depression extends to Kazakhstan with a depth of $\sim 600 \mathrm{~m}$, which can be divided into two secondary-order tectonic units: the Emin sag of southeastern part, and the Yumin sag of the western part.

\section{Favorable exploration areas}

By analyzing the data from the field outcrops and the hydrocarbon source rocks of the Tacan 1 well, we determined that Carboniferous hydrocarbon source rocks have overprinted existing igneous rocks. The most prevalent rock type is primarily argillaceous with carbonaceous mudstone and coal being less common. Abundant organic matter typically makes Upper Carboniferous rocks more productive than the Lower Carboniferous rocks. Although both evolution degrees are generally observed, there is still a potential for residual hydrocarbons ( $\mathrm{Gu}$ and Fang, 2011; Jiang et al., 2012; Pei et al., 2012).

The depth chart of the Tacheng basin basement reflects the various sedimentary developments of the depression. The depression in the southeastern area is about 3000 square kilometers, and the depth of the basin basement is about $1200 \mathrm{~m}$. The Tacan 1 well in the Yumin northern depression has allowed for sampling of the dark mudstone, silty mudstone, carbonaceous mudstone and setting gray mudstone while drilling, and the total thickness is $306 \mathrm{~m}$. Although the Emin and $\mathrm{Yu}-$ min sags have the same conditions of tectonic evolution and similar sedimentary conditions, the Emin sag has a greater thickness of sediments in the front of mountain. Likewise, the condition of the Carboniferous and Permian sedimentary is better. The Emin sag is the largest sedimentary unit of Tacheng basin with excellent hydrocarbon source rock conditions for oil and gas exploration. Above all, we find that the most favorable area in the Tacheng basin for oil and gas development is the Emin sag.

\section{Conclusions}

1) The main part of the Tacheng basin is a Late Paleozoic continental margin of volcanic rock that de- veloped on the basement of an Early Palaeozoic island arc. Its evolution involves significant evidence of the presence of a tectonic double-base. After the formation of metamorphic rocks, the condition of the basement achieved its present formation.

2) Three sides of the Tacheng basin are surrounded by folded mountain systems. Old and new formations in the north are a normal unconformity contact relation. A thrusting nappe in the south and south-east controls the structure in the zone between the basin and the mountains, especially the multiple nappe sequence in the southeast, forming large-scale Piedmont dustpanlike sags.

3) According to the variable characteristics of the basal patterns, the Tacheng basin can be divided into four first-order tectonic units: a central uplift, a northern depression, a southeastern depression and a west depression. Furthermore, the southeastern depression can be subdivided into the Emin and Yumin sags.

4) The Emin sag is the largest tectonic unit in the Tacheng basin with a better basis for sedimentary filling than the location of the Tacan 1 well. In addition, favorable conditions are found within the hydrocarbon source rocks, so we suggest that the Emin sag is a promising area for oil and gas exploration.

\section{References}

Bureau of Geology and Mineral Resources in Xinjiang (1985). Geological Maps of 1:2 000 000. Geological Publishing House, Beijing, 1 (in Chinese).

Dong L H, Qu X, Zhu Z X and Zhang L C (2010). Tectonic evolution and metallogenesis of Xinjiang. Geology of Xinjiang 28(4): 351-357 (in Chinese with English abstract).

Feng Q W (2009). Inversion of Gravity and Magnetic Studies of Tacheng Basin Basement. [PhD Dissertation]. Xinjiang University, Ürümqi, 48-51 (in Chinese with English abstract).

Feng Q, Zheng G H, Zhang X F and Chen C (2009). Tacheng basin joint inversion of gravity, magnetic, electricity, seismic of Carboniferous basement. Journal of Xinjiang University 26(3): 242-247 (in Chinese with English abstract).

Gu Y L and Fang X Y (2011). Paleozoic source rock evaluation in Tacheng basin. Scientific and Technological Advice (28): 123 (in Chinese with English abstract).

Jiang Y Q, Gao G, Liu G D, Wang X L, Pei L X, Xiang B $\mathrm{L}$ and Tang $\mathrm{Y}$ (2012). Tacheng basin characteristics and hydrocarbon-generating potential of hydrocarbon source rock of Carboniferous in China. Test Geology for Oil 34(4): 427-436 (in Chinese with English abstract).

Pei L X, Gao G, Wang X L, Liu G D, Zhang Y Q and 
Tang Y (2012). Jeminay basin in northern Xinjiang and characteristics of Carboniferous hydrocarbon source rock in Tacheng basin. Natural Gas in Earth Sciences 23(1): 88-90 (in Chinese with English abstract).

Wang G P and Wu G T (1990). Geology Memories of Xinjiang. Geological Publishing House, Beijing, 112-194 (in Chinese).

Zhang C and Huang X (1992). Age and environment of ophiolite of western Junggar, Xinjiang. Geology Reviews 38(6): 510-512 (in Chinese with English abstract).

Zhang L C, Liu D Q and Tang Y L (1990). Xinjiang's Treasure. Xinjiang People's Press, Ürümqi, 269-231 (in Chinese).

Zhu B Q and Feng Y M (1994). Plate structure and evolution in West Junggar, Xinjiang. Xinjiang Petroleum Geology 12(2): 103-104 (in Chinese with English abstract). 